\title{
The many facets of the matricelluar protein periostin during cardiac development, remodeling, and pathophysiology
}

\author{
Russell A. Norris • Ricardo Moreno-Rodriguez • \\ Stanley Hoffman • Roger R. Markwald
}

Received: 17 June 2009 / Accepted: 20 August 2009 / Published online: 2 October 2009

(C) The Author(s) 2009. This article is published with open access at Springerlink.com

\begin{abstract}
Periostin is a member of a growing family of matricellular proteins, defined by their ability to interact with components of the extracellular milieu, and with receptors at the cell surface. Through these interactions, periostin has been shown to play a crucial role as a profibrogenic molecule during tissue morphogenesis. Tissues destined to become fibrous structures are dependent on cooperative interactions between periostin and its binding partners, whereas in its absence, these structures either totally or partially fail to become mature fibrous entities. Within the heart, fibrogenic differentiation is required for normal tissue maturation, remodeling and function, as well as in response to a pathological myocardial insult. In this review, aspects related to the function of periostin during cardiac morphogenesis, remodeling and pathology are summarized.
\end{abstract}

Keywords Periostin - Matricellular proteins - Fasciclin . Development · Matricellular · Collagen · Post-EMT · Valve morphogenesis $\cdot$ Cardiac remodeling

$\begin{array}{ll}\text { Abbreviations } \\ \alpha \text {-SMA } & \alpha \text {-Smooth Muscle Actin } \\ \text { AV } & \text { Atrioventricular } \\ \beta \text { igH3 } & \text { TGF } \beta \text {-induced gene-Human Clone } 3 \\ \text { BMP } & \text { Bone Morphogenetic Protein } \\ \text { DDR2 } & \text { Discoidin Domain Receptor-2 } \\ \text { ECM } & \text { Extracellular Matrix } \\ \text { ED } & \text { Embryonic Day }\end{array}$

R. A. Norris · R. Moreno-Rodriguez · S. Hoffman •

R. R. Markwald $(\bowtie)$

Department of Cell Biology and Anatomy,

Medical University of South Carolina,

BSB Suite 601, 173 Ashley Avenue,

Charleston, SC 29425, USA

e-mail: markwald@musc.edu

$\begin{array}{ll}\text { EDS } & \text { Ehlers-Danlos Syndrome } \\ \text { EPDC } & \text { Epicardial-Derived Cell } \\ \text { FAK } & \text { Focal Adhesion Kinase } \\ \text { HSPG } & \text { Heparin Sulfate Proteoglycan } \\ \text { MHC } & \text { Myosin Heavy Chain } \\ \text { MLC } & \text { Myosin Light Chain } \\ \text { OFT } & \text { Outflow Tract } \\ \text { OSF-2 } & \text { Osteoblast Specific Factor-2 } \\ \text { PLF } & \text { Periostin-Like Factor } \\ \text { ROCK } & \text { Rho Kinase } \\ \text { SPARC } & \text { Secreted Protein, Acidic, Rich in Cysteine } \\ \text { SRF } & \text { Serum Response Factor } \\ \text { VEGF } & \text { Vascular Endothelial Growth Factor } \\ \text { YY1 } & \text { Yin Yang-1 }\end{array}$

\section{Introduction}

The periostin gene was initially cloned from a mouse calvarial cell line (MC3T3-E1) and originally named osteoblast specific factor-2 (OSF-2) (Takeshita et al. 1993). This name was eventually changed to "periostin" due to its intense expression within the periosteum and periodontal ligament as well as to avoid any confusion with a transcription factor with the same name (Ducy et al. 1997; Horiuchi et al. 1999). The encoded periostin protein has a molecular weight of $\sim 90 \mathrm{kDa}$ and contains four domains that are highly related in amino acid sequence to the ancestral fasciclin gene in Drosophila (Horiuchi et al. 1999).

Periostin is one of four known mammalian genes that contain fasciclin domains. The other fasciclin genes are: TGF $\beta$-Induced Gene-Human clone 3 (a.k.a $\beta$ igH3) (Skonier et al. 1992), as well as stabilin 1 and 2 (Politz et al. 2002). BigH3 shares $49 \%$ overall amino acid homology $(70 \%$ 
homology in the fasciclin domain) with periostin, whereas the stabilin proteins are significantly more divergent. Periostin protein has a signal sequence (targeting it for secretion), four-coiled fasciclin-like repeats, an aminoterminal cysteine-rich region (EMI domain), and heparinbinding domains present in the carboxyl tail. Although the domains for periostin have been described based on sequence homology, it is still unclear as to the function of each of these domains. Interestingly, Western analysis and genomic sequencing have revealed that as many as six carboxyl splice variants may be produced from the periostin locus (Litvin et al. 2004; Shimazaki et al. 2008). One of these variants has been termed "Periostin-like Factor" or "PLF", which itself is not a separate member of the fasciclin gene family as the name would imply, but rather is one of the naturally occurring splice variants from the periostin locus (Litvin et al. 2004).

Data ascribing function to these unique variants has only begun to be examined. As isoform-specific expression has been found in a variety of cell and tissue types, a more comprehensive understanding of periostin variant function will undoubtedly yield new insight into developmental and pathological processes. Whereas periostin clearly has major roles in both tooth development (Kii et al. 2006) and cancer (Ruan et al. 2009), for the purpose of this review we will focus on findings related to the current understanding of periostin during cardiac development and pathology, as well as the known molecular mechanisms by which it elicits these activities.

\section{Expression of periostin during cardiac development}

The expression of periostin during chick and mouse cardiac development has been examined, with the mouse patterns more thoroughly studied (Kern et al. 2005; KruzynskaFrejtag et al. 2001; Lindsley et al. 2005; Norris et al. 2004, 2005, 2008b). To date, no difference in expression patterns have been detected between the two species except in the mural leaflet of the tricuspid valve, where the avian system has a muscular/myocardial leaflet (and no periostin expression) in lieu of a fibrous leaflet as seen in the mouse. During cardiac morphogenesis, periostin is expressed primarily by mesenchymal tissues that will give rise to the atrioventricular and outflow (semilunar) valve leaflets, the annulus fibrosae, chordae tendineae, and ventricular fibroblasts. Here, we focus on specific expression of periostin within these structures.

Periostin protein is first detected within mesenchyme of the atrioventricular (AV) canal that is formed by the transformation of endothelial cells into mesenchyme (EMT) beginning at embryonic day (ED) 9.5 (Norris et al. 2008b). As EMT progresses, periostin expression, initially cytoplasmic, becomes predominantly extracellular as the mesenchyme of the AV canal (junction) expands between ED 10 and 12.5 to form "endocardial cushions", the primordia of future valves and septa. Mesenchymalized cushions also form in the proximal and distal regions of outflow tract (OT) cushions between ED 10.5 and ED12.5. In the outflow tract cushions, periostin is expressed by both endothelial-derived mesenchyme as well as by neural crest cells (Lindsley et al. 2007; Norris et al. 2008b). Distally the OT cushions develop into the aortic and pulmonary (semilunar) valve leaflets during which time (E13.5 and E16) they strongly express periostin. Expression within the aortic valve appears to be widespread throughout the leaflet, whereas the pulmonary valve exhibits more intense expression on the ventricular aspect of the leaflet. Weak expression is also evident within the wall of the aorta and the anterior aspect of the interventricular septum, in the ventral mesenchyme of the fused AV cushions. The developing mitral and tricuspid $\mathrm{AV}$ valves also exhibit intense periostin staining from E13.5 through E16. Additionally, periostin is expressed in the epicardial epithelium at E13.5 and in epicardially-derived mesenchymal cells that also are generated by EMT. Some epicardially-derived cells (EPDC) migrate into the myocardial wall and differentiate into interstitial fibroblasts. Other EPDCs remain within a groove or sulcus that completely encircles the external surface of the AV junction at E16.

Over time, the AV junctional myocardium is lost and the sulcus (EPDC) mesenchyme directly contacts endocardially-derived cushion mesenchyme. Both populations of mesenchyme intensely express periostin: the EPDC sulcus mesenchyme becomes the fibrous annulus which serves to anchor the base of the mitral and tricuspid valve leaflets derived from $\mathrm{AV}$ endocardial cushion mesenchyme. Additionally, strands of periostin protein are seen extending caudally from the base of the interventricular septum to its apex (Norris et al. 2008b). This pattern of expression in the septum coincides with the left and right bundle branches of the central AV conduction system. Just after birth, neonatal expression of periostin intensifies in the interstitial fibroblastic cells of the myocardial wall and in both inlet (AV) and OT valves, which do not complete their morphogenesis until after birth (Borg and Markwald 2007; Norris et al. 2008b; Oka et al. 2007). Periostin is also expressed in the tendinous supporting structures (chordae tendineae) of the $\mathrm{AV}$ valves. In the adult mouse, periostin expression continues for life, being most intensely expressed within the chordae tendineae, fibrous annulus and $\mathrm{AV}$ and arterial valves (Fig. 1). Expression in all leaflets is more predominantly confined to the ventricular aspects of the leaflets, i.e. the surface where sheer stress is greatest. After the neonatal period, periostin expression diminishes in the myocardial walls. 


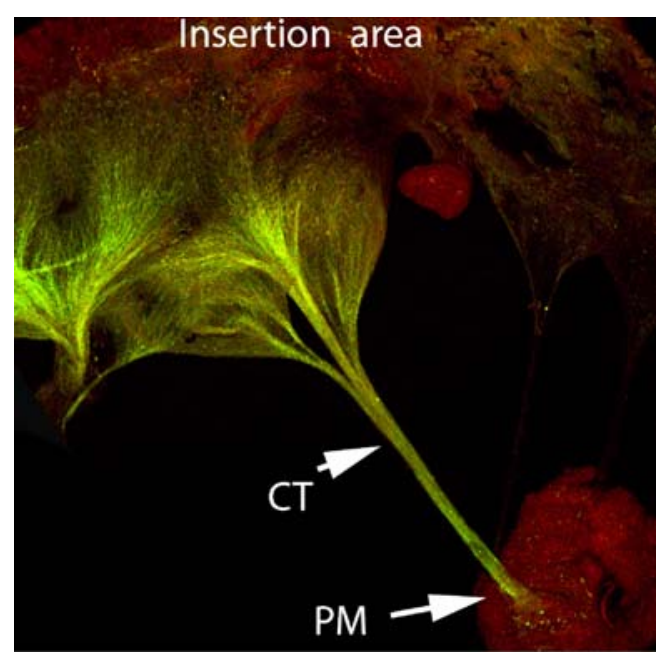

Fig. 1 Expression of periostin in the adult murine tricuspid valve. Immunohistochemical staining of Periostin (green) in the adult murine tricuspid valve leaflet showing robust staining in the chordae tendineae (CT) and valve leaflet. Expression of periostin in nonfibrous tissue (papillary muscle-PM) is negligible

From these descriptive studies, it was deduced that periostin may function to promote the differentiation of mesenchymal tissues into mature fibroblastic structures (Norris et al. 2008b). This is based on expression data showing that the highest levels of periostin are found in mesenchymal tissues (derived by an EMT process) that are fated to become fibrous structures (e.g. valve leaflets, chordae tendineae, ventricular fibroblasts). Data generated from gain and loss of function experiments would later add significant insight into the validity of this hypothesis.

\section{Gain and loss of function: the dynamic role of periostin during cardiac development}

To date, three periostin knockout mice have been generated with each showing similar phenotypes (Kii et al. 2006; Norris et al. 2007; Oka et al. 2007; Rios et al. 2005). The majority of knockout mice are viable and smaller on average than littermate control animals. Approximately $20 \%$ appear to die either early in development or during the neonatal period. A close examination of the cardiac structures in which periostin was expressed yielded new and intriguing insight into not only the function of periostin during heart development, but also in key differentiation processes guiding proper valve maturation.

The AV and OFT cushions in the periostin knockout mice appear to undergo both endocardial and epicardial EMT as mesenchymal cells are clearly present within the cushions at later stages of development, indicating that an endothelial to mesenchymal transformation had occurred (Norris et al. 2008b; Snider et al. 2008). Most genes crucial for EMT result in early embryonic lethality when genetically removed. The fact that most periostin-null mice live to birth suggests that if periostin has a role in valvulogenesis, it would be during the "post-EMT" morphogenesis of cushions into valve leaflets. Thus, the morphological development of the valves following this initial EMT period (so-called "Post-EMT") in the periostin knockout animals was analyzed by two independent groups (Norris et al. 2008b; Snider et al. 2008). The findings demonstrated that periostin-null mice exhibit a primary defect in the differentiation of valve mesenchymal precursor cells into fibroblasts. The outcome of abnormal differentiation was altered morphogenesis of the leaflets and their supporting apparatus, as well as retention of myocardial structures that normally regress or are lost.

\section{Periostin regulates differentiation of valve leaflet progenitor cells}

As demonstrated by Norris et al (Norris et al. 2008b) and subsequently confirmed by Snider et al (Snider et al. 2008), a subpopulation of cushion mesenchyme in the periostinnull mice aberrantly differentiate into MF20/myosin heavy chain (MHC) positive myocytes. This finding was further tested in vitro and it was demonstrated that periostinknockout cushion mesenchymal cells express myocardial markers, MHC and MF20 (sarcomeric myosin), whereas wild-type cells fail to express these markers. Addition of purified periostin to these cultures reduced the expression of myocardial markers, indicating that periostin is required for the inhibition of a myocardial gene program in prevalvular mesenchymal cells.

Further evidence for periostin functioning in an antimyocardial pathway was recently presented. In a report by Niu et al. (2008), serum response factor (SRF) was shown to repress Gata-6 and periostin expression in early cardiogenic mesoderm. Conditional ablation of SRF in early cardiogenic mesoderm (that normally differentiates into cardiac muscle) induced the expression of periostin and Gata-6. Additionally, this report demonstrated that the epicardium of periostin-null mice had ectopic pockets, or foci, of MHC-positive cells suggesting aberrant epicardial to myocardial differentiation (Niu et al. 2008). In addition to a role for periostin in blocking myocardial differentiation, it has recently been demonstrated that endocardiallycushion mesenchyme from periostin-null mice exhibit decreased levels of collagen I, a characteristic of cells that differentiate into fibroblasts (Norris et al. 2008b). Nullcushion cells also were devoid of the collagen receptor, DDR2 (Discoidin Domain-2), which has been shown to be a cardiac fibroblast marker and functions as an important regulator of collagen fibrillogenesis (Norris et al. 2007). 
Exogenous addition of periostin in vitro "rescued" the DDR2 and collagen deficit, demonstrating that periostin can promote fibrogenesis through a DDR2/collagen pathway. Consistent with periostin being a matricellular protein, periostin has been shown to bind to collagen during fibrillogenesis, thus affecting the diameter of collagen fibers and cross-linking (Kii et al. 2006; Norris et al. 2007; Shimazaki et al. 2008).

The potential for periostin to block myocardial differentiation while promoting fibrogenesis was further evaluated in the chick (Norris et al. 2009). In this system, AV cushion mesenchyme was isolated and tested in hanging drop and novel cardiotube assays. Expression levels of perisotin were manipulated using specific adenoviruses (anti-sense and over-expression). Consistent with the previous mouse reports, it was found that inhibiting periostin in chick $\mathrm{AV}$ mesenchyme not only decreased collagen expression, but also induced myocardial markers (MHC, MLC, and desmin). The mechanism(s) by which periostin may elicit its profibrogenic and anti-myocardial effect on mesenchymal cell differentiation is currently unknown, but clearly suggests roles for SRF, DDR2, collagen, and specific integrin receptors (as discussed later).

\section{Periostin is required for fibrous maturation of $\mathrm{AV}$ leaflets and their supporting structures}

As described above, the role of periostin during valve development appears to be primarily in promoting the differentiation of mesenchymal cells into fibroblasts. In its absence (loss of function) this same population of mesenchymal cells acquires the potential to differentiate into other mesodermal lineages (e.g. cardiac myocytes), demonstrating that $\mathrm{AV}$ cushion mesenchyme is multipotential but normally becomes fibroblastic in the presence of periostin. As cushion mesenchyme and epicardially-derived mesenchyme provide a morphogenetic blueprint for the future valve leaflets, it is interesting to note that the adult atrioventricular valves display similar differentiation defects, as did the embryonic tissues, suggesting a continuation and amplification of these developmental anomalies.

Adult periostin-null mitral and tricuspid leaflets exhibit a significant reduction in collagen I protein with the coincident presence of excessive myocardial tissue, in addition to aggrecan and proteoglycan accumulation (Norris et al. 2008b; Snider et al. 2008). These defects, which are not observed in normal valve leaflets, result in failure of proper stratification, attenuation, and alignment of collagen, leading over time to myxomatous valve degeneration and/or fibroelastic deficiencies. Atomic force microscopy studies revealed a smoother appearance and an increase in compliance (decrease in stiffness) of the leaflet and chordal structures, which would be expected with a fibroelastic deficiency. Although it has not yet been examined, these changes in leaflet structure and composition would be expected to greatly influence the biomechanical properties of the leaflets, which could lead to valve prolapse and retrograde blood flow (regurgitation). In the periostin-null mouse, aortic regurgitation has been seen.

Aside from the valve leaflets, defects in the fibrous supporting structures were observed in periostin knockout mice and in avian model systems (Kolditz et al. 2007; Norris et al. 2008b). The two main structures affected are the chordae tendineae and the annulus fibrosae. The chordae tendineae anchor the ventricular aspect of the leaflets to the myocardial wall via the papillary muscles and are required for stability of the valve complex. Periostinknockout mice exhibit shortened chordae tendineae that contain ectopic myocardial tissue, fail to branch during postnatal life, and have an increase in chordal diameter. Formation of the chordae tendineae is a complex process that has not been thoroughly unraveled. It is hypothesized that formation of the chordal complex is initiated by a myocardial remodeling event near the shoulders of the base of the ventricular wall (de la Cruz 1998). Intercellular spaces appear within the myocardium of the free wall of the left and right ventricle, adjacent to the left and right lateral cushions of the AV canal at the "myocardial shoulders". These intercellular spaces eventually coalesce and divide the myocardial free wall into two layers: subepicardium and subendocaridum. It is the subendocardial layer that is connected to the mural leaflet and is later remodeled into the chordae tendineae and papillary muscle. It is in these myocardial shoulders that periostin expression is most abundant.

Periostin-null mice fail to remodel the AV junctional tissue properly. The excavation of the myocardium, as is normally seen, fails to occur and the formation of chordae tendineae either does not occur, or the chords are truncated and branching is diminished (Norris et al. 2008b). Additionally, delamination of the septal leaflet of the tricuspid valve fails to occur. These defects in chordae size, in addition to valvular dysplasia, would be expected to result in displacement of the leaflets and their failure to properly coapt. Although the mechanism is currently unknown, it is hypothesized that periostin promotes the removal and coalescence of this myocardial tissue by either inducing a transdifferentiation of the myocardium or in promoting apoptosis. To date, there has been no evidence that periostin promotes apoptosis of myocardial tissue. Recently, data were presented showing that forced expression of periostin in cultured neonatal myocytes promoted collagen gel invasion and smooth muscle marker activation, substantiating a role for periostin in myocyte transdifferentiation (Norris et al. 2008a).

Although the annulus fibrosae that anchors AV valve leaflets and insulates atrial myocardium from ventricular 
myocytes has not been carefully examined in the mouse models of periostin deficiency, elegant studies were performed in the quail system. Kolditz et al. describe that a delay in the formation and migration of the epicardium results in persistence of accessory electrical pathways (Kolditz et al. 2007). It is well established that these accessory pathways, which can cause arrhythmias in humans (e.g. Wolff-Parkinson-White syndrome), consist of abnormal cardiac musculature that crosses the $\mathrm{AV}$ groove/sulcus (Becker et al. 1978). By using this model system in chick it was discovered that the epicardiumderived cells traveling through the atrioventricular border via the $\mathrm{AV}$ sulcus are crucial for proper annulus formation and electrical isolation. As these cells migrate they abundantly express periostin and collagen. A delay in the formation of the epicardium resulted in failure to form a complete fibrous annulus, and was correlated with loss of periostin expression at the $\mathrm{AV}$ junction and the persistence of AV junctional myocardial cells. Retention of periostin expression in AV junctional myocardial cells altered electrophysiological features (short PR interval, slurring of the QRS complex, and prolonged QRS), resulting in large electrically-active accessory pathways transmitting through the right and left lateral free wall. These results suggest that epicardial delivery of periostin to the sulcus region of the $\mathrm{AV}$ junction is required for sulcus cells to differentiate into fibroblasts of the annulus, and in the absence of periostin, myocardial retention occurs, resulting in electrophysiological defects of the AV junctional myocardium.

\section{Summary of valve development and maturation}

Periostin has been described as the first matricellular protein that functions as a hierarchical molecular switch to promote the differentiation of mesenchymal cells into a fibroblastic lineage, while suppressing their transformation into myocytes. In addition, periostin may function to remodel junctional myocardial tissue, a process indispensable for the formation of the chordae tendineae and annulus fibrosae, by promoting transdifferentiation (or apoptosis) of the resident myocytes. Regardless of the mechanism, both chick and mouse data promote the idea that periostin is a matricellular protein that plays a unique role in valvulogenesis, and is necessary for the proper morphogenesis and maturation of mesenchymal tissues into their final fibrous structures.

\section{Periostin functions to promote neonatal and ventricular remodeling}

Heart development does not end with birth. During the postnatal period, the heart (valves and myocardial walls) acquires its mature phenotype as it adapts to sudden changes in systemic blood pressure (Guignard 1986; Jones and Jose 2004; Kent et al. 2007a, b). These adaptive events, often referred to as normal remodeling, are triggered by biomechanical, electrical and chemical signals that result in the sculpting and controlled growth (hypertrophy) of the myocardial wall (Banerjee et al. 2006, 2007; Borg et al. 1984; Camelliti et al. 2005; Carver et al. 1991; Terracio et al. 1990). Typically, normal neonatal remodeling is observed as (i) an increase in fibroblast numbers (hyperplasia) and new formation of fibrous ECM components, especially collagen and (ii) hypertrophy of existing myocytes and their subsequent exit from the cell cycle. Understanding the function of specific genes expressed during this time of active remodeling may provide clues as to how the heart requires a specific genetic blueprint capable of sensing and responding to changes in blood pressure.

Based on RT-PCR, Western analyses, and immunostaining, it has been shown that periostin expression by ventricular cardiac fibroblasts is abundant and peaks during early neonatal life, subsequently declining to barely detectable levels in adult life (Norris et al. 2008a; Oka et al. 2007; Shimazaki et al. 2008). It is now thought that periostin is important for the differentiation of precursor cells into cardiac fibroblasts during the neonatal period. This is based, in part, on flow cytometry data showing that the neonatal periostin null-myocardium contains a significant population of cells $(30 \%)$ that cannot be identified by standard markers that sufficiently identify $>95 \%$ of the cells in wild-type mice (Norris et al. 2008a). The reason for this change in cell numbers is unknown but may be due to a developmental defect in cardiac fibroblast progenitor cell differentiation, migration, or both.

Understanding the role of periostin in this process of normal neonatal ventricular remodeling may be applicable to the study of adult remodeling following cardiac injury since many of these developmental and/or neonatal programs are reactivated ("reawakened"). Following cardiac injury in the adult, expression of periostin is highly upregulated in resident fibroblasts associated with the wound area, and has been shown to be important for the scar formation process (Norris et al. 2008a; Oka et al. 2007; Shimazaki et al. 2008). Periostin-null mice receiving a myocardial infarction have an increased susceptibility to cardiac rupture and exhibit decreased circumferential strain and passive stiffness. However, periostin-null mice that survive the initial myocardial insult were less susceptible to fibrotic scarring and exhibited better ventricular performance than wild-type controls. The mechanisms by which this can be explained have recently begun to be examined. The periostin-null mice exhibited reduced de novo collagen synthesis and cross-linking, which resulted in frequent cardiac rupture (Shimazaki et al. 2008). The overriding 
causal defect appears to be a decrease in $\alpha$-SMA-positive cells within the infarct, and an overall decrease in the recruitment of cardiac fibroblasts to the infarct region. The migration of these cells into the injury site appeared to be at least partially dependent on FAK and downstream AKT phosphorylation. The origin of the fibroblasts associated with an injury site may stem not only from resident cardiac fibroblasts, but also from the systemic circulation. Recent studies have demonstrated that hematopoeitic stem cells engraft into the heart following cardiac injury and express high levels of periostin, presumably defining these cells as differentiated cardiac fibroblasts (Visconti and Markwald 2006). Thus, if the role of periostin in heart development is primarily to promote differentiation of mesenchymal progenitor cells into fibroblasts while inhibiting differentiation into alternative mesodermal lineages (e.g cardiomyocyte), it is enticing to propose, that blocking or silencing periostin expression in circulating progenitor cells following cardiac injury may attenuate fibrous myocardial remodeling by inducing (or redirecting) their differentiation into a myocardial lineage. .

The potential for developing novel therapies for blocking periostin expression may prove useful in tipping the balance from fibroblast infiltration to that of myocardial regrowth. In addition to this potential, data presented by Kuhn et al. suggest that adding recombinant periostin in a patch to the infracted area promotes proliferation of adult cardiomyocytes (Kuhn et al. 2007). To date, this interesting finding has not yet been corroborated by other groups working with periostin. In fact, a recent effort to specifically determine if periostin promoted cell cycling in normal or injured cardiomyocytes was not successful, suggesting that the primary role for periostin is to promote fibroblastic differentiation and not myocyte proliferation (Kuhn et al. 2007).

Although these studies are in their infancy, it is important to note the striking differences between primitive species and mammals. For example, zebrafish and newts are clearly capable of myocardial regeneration whereas in mammals it is not readily evident (Ausoni and Sartore 2009). One explanation for this difference might be the number and distribution of fibroblasts. Fibroblasts account for the majority of nonmuscle cells in mammals but they are rare in lower species and occur interspersed within the subepicardial layer of the heart. This difference in cellularity correlates with the increased hemodynamic load placed on mammalian hearts after birth, which must be sustained throughout life. Thus differences in biomechanical signaling might induce more extracellular matrix-producing cells (fibroblasts) in mammals. The near absence of fibroblasts in newts, zebrafish, and salamanders may correlate with the relative lack of periostin expression. Under such conditions (as in null mice) an increased number of progenitor cells that migrate into the heart may have differentiated into new cardiomyocytes. Alternatively, reduced levels of periostin may potentiate regeneration by promoting proliferation of adult myocardial cells or their immediate precursors. By trying to mimic such inhibition of periostin in mammals, might this be a possible route to promoting or enhancing myocardial regeneration?

\section{Periostin functions as a matricellular protein through specific cell-surface and matrix interactions}

Intracellular signals respond to the periostin call

Unfolding the mechanisms by which periostin functions to promote differentiation of endothelial or epicardiallyderived mesenchyme clearly invokes not only its interactions with the extracellular milieu, but also with the cell surface. It is through the specific interactions with $\alpha \mathrm{v} / \beta 3$ and $\beta 1$ that periostin functions to elicit important remodeling of $\mathrm{AV}$ cushion mesenchyme (Butcher et al. 2006). Stimulation of these receptors activates the PI-3 kinase and Rho kinase (ROCK) pathways, which are essential for promoting stress fiber and filipodia formation. Rho kinase, a serine/threonine protein kinase, in conjunction with focal adhesion kinase (FAK) stimulates adhesion and cell migration by enhanced formation of filipodia. The mechanisms by which periostin/integrin signaling induces these responses are not known. One possibility suggested by integrin-based signaling in other cell systems may involve specific interactions between ROCK and the actin-binding protein Filamin-A (Feng and Walsh 2004; Zhou et al. 2007). The small GTPase Rho, and its effector ROCK, regulate actin cytoskeletal organization through specific interactions with Filamin-A (Ohta et al. 2006; Ueda et al. 2003). These molecular interactions, in turn, are required for stabilizing orthogonal actin networks required for locomotion. It is interesting to note that Filamin-A can also bind specifically to the cytoplasmic tails of the integrin pairs shown to bind periostin (Kim et al. 2008). Thus it is conceivable that periostin can stimulate movement of filipodia via actin cytoskeletal remodeling that is mediated through either a kinase-dependent (Rho and/or FAK) or independent (receptor-Filamin A mediated) events. It is important to note that not only is the Rho pathway essential for promoting migration and cell-shape changes via periostin and Filamin-A, but it has also been shown to: (i) block muscle differentiation and (ii) mediate cardiac fibrosis in an ischemic/reperfusion cardiomyopathy model by regulating fibroblast precursor cell differentiation (Haudek et al. 2009). Thus, in the context of the periostin-null mouse, decreased expression or phosphorylation of Rho and/or FAK could be anticipated to decrease cell migration and formation of 
filipodia, as well as to disrupt normal processes of differentiation.

In addition to migration and differentiation, valvular precursor cells must also find a mechanism of remodeling the surrounding matrix that is required for sculpting the cushions into cusps and leaflets. Uncontrolled migration and proliferation would undoubtedly result in a valve leaflet with a randomized distribution of ECM components that would correlate with impaired compaction/attenuation in sculpted structures where shape dictates function. Thus, the leaflet must continually remodel itself during embryonic and fetal life to acquire the proper geometry. One way in which this might occur is through the potential of valve precursor cells to compact (and align) collagen fibers. It was recently shown that cushion cells increase collagen compaction through a periostin-dependent, integrin-based signaling mechanism, originally demonstrated by Butcher et al. using the chick system (Butcher et al. 2006). This finding was consistent with the phenotype of the periostin-null mouse in which the prevalvular cushions of knockout mice hearts were isolated and placed in free-floating gels, where they exhibited a phenotype in which there was significant reduction in collagen compaction (Snider et al. 2008).

Though periostin, unlike $\beta$ igH3, lacks a consensus RGD integrin-binding motif, there are abundant data indicating that periostin binds to specific integrin pairs. Depending on the cellular and/or tissue context, periostin has been shown to interact with integrins: $\alpha \mathrm{v}, \beta 3, \beta 1, \beta 5$, and $\beta 4$ (Baril et al. 2007; Butcher et al. 2006; Gillan et al. 2002; Ruan et al. 2009). The specific periostin-integrin interaction domain has yet to be fully characterized. However, the integrinbinding domain for $\beta$ igH3 has been mapped to the fasciclin domains. Based on the high degree of sequence conservation between these two related proteins, specifically within their fasciclin domains, we anticipate that these integrinbinding motifs within periostin will also be discovered in the fasciclin domains.

It is interesting to note that the matricellular proteins periostin, $\beta i g H 3, \mathrm{CCN} 1$, and $\mathrm{CCN} 2$ are capable of interacting with $\alpha \mathrm{v}, \beta 3$, and $\beta 1$ integrins and are each expressed in the developing heart (Chen and Lau 2009; Chuva de Sousa Lopes et al. 2004; Mo and Lau 2006; Surveyor and Brigstock 1999). It is not known whether there is competition among these proteins for the same integrin pairs, or if specific heterodimeric or oligomeric clusters of these proteins provide additional selectivity for the various integrins. New findings demonstrating the ability of periostin and $\beta \mathrm{igH} 3$ to specifically interact (via their amino terminal EMI domains) would suggest cooperation versus competition, although both possibilities persist (Kim et al. 2009). The precise identification of the periostin-integrin interacting regions will provide significant insight into the mechanisms by which periostin regulates integrin clustering and intracellular dynamics including kinase signaling, cytoskeletal remodeling, cell motility and collagen compaction. The intracellular signaling cascades dependent on periostin signaling are only now beginning to be examined in the context of early valvulogenesis and postnatal valve leaflet maturation. These initial findings in cushion and valve progenitor cells, however, already provide an important framework by which we can advance our understanding of how matricellular proteins like periostin can stimulate cell behavior, and ultimately tissue structure. Moreover, it should be noted that other receptor and membrane-bound complexes may, and probably do, interact with periostin. In fact, the carboxyl terminus of periostin has been demonstrated to interact with heparin (Sugiura et al. 1995). Thus, the possibility remains that periostin can interact with cell-surface heparin sulfate proteoglycans (HSPGs), such as the syndecans, glypicans, perlecan, agrin, and/or collagen XVIII. These interactions are currently unknown, but should be examined as HSPGs are intricately involved in developmental and disease processes.

\section{Periostin and extracellular interactions}

In addition to interacting with the cell membrane via integrins, periostin also interacts with extracellular matrix proteins including fibronectin, tenascin- $\mathrm{C}$, $\beta$ igH 3 , collagen V, and collagen I (Kii et al. 2006; Kim et al. 2009; Norris et al. 2007; Takayama et al. 2006). Due to the expression of periostin in collagen- rich connective tissues, a majority of the work focusing on periostin interactions has involved periostin and collagen I. Intrinsic to these interactions are the evolving roles that periostin plays in promoting collagen fibrillogenesis (Norris et al. 2007). Collagen fibrillogenesis is a multistep process that involves linear and accelerative growth, followed by lateral growth and subsequent fusion of collagen fibers (Canty and Kadler 2002; Canty and Kadler 2005; Kadler et al. 1996). Based on studies of collagen fibrillogenesis in vitro, it has been suggested that there is a correlation between collagen fibril diameter and the mechanical properties of collagen-based connective tissues (Christiansen et al. 2000). By altering collagen diameter, the structural and functional integrity of the connective tissue is compromised. Morphometric studies of transmission electron micrographs demonstrated a reduced diameter of collagen fibrils in periostin-knockout mice compared to that in wild-type mice, indicating changes in collagen fibril maturation and assembly (Norris et al. 2007). These findings suggest that the binding of periostin to collagen can serve to regulate the lateral association of collagen microfibrils, thereby affecting fiber diameter. This suggestion is further supported by two other key findings: (i) periostin binds directly to collagen I and 
(ii) periostin-null mice exhibit a reduction in collagen crosslinking. These collagen interactions may be a common function of matricellular proteins, as similar results have been obtained in the context of SPARC-deficient animals (Bradshaw et al. 2003).

The mechanisms by which SPARC affects collagen fibril diameter also appear to be through the direct binding to collagen type I. Additionally, SPARC is a substrate for transglutaminase, an enzyme that catalyzes cross-links between proteins (Aeschlimann et al. 1995). It is unclear at the present time whether periostin is also a substrate for transglutaminase or whether other enzymes, such as lysyl oxidase, are involved in cross-linking collagen moieties. Additional biomechanical assays have been used to more fully appreciate the role of periostin in regulating and maintaining proper biomechanics of collagen-rich, connective tissues. Overexpression of periostin in valve progenitor cells (cushion mesenchyme) results in increased tissue viscosity, as measured by using surface tensiometry and tissue fusion assays. Whether this effect involves induction of procollagen expression, enhanced fibril maturation and stabilization, and/or resistance to the natural process of collagen fibril turnover remains to be determined. In addition, a variety of biophysical and biomechanical experiments have demonstrated that collagen-rich connective tissues such as the skin, valve leaflet, and chordae tendineae of periostin-null mice exhibit a decrease in stiffness/compliance when compared to their wild-type couterparts (Norris et al. 2007). The domain(s) in periostin that bind collagen have not yet been determined but their identification could prove critical for furthering our understanding of collagen fibrillogenesis and fibrotic processes.

Whereas the fasciclin and the carboxyl-terminal alternatively-spliced domains have received much scientific attention, the function of the amino-terminal end of the protein is largely unstudied. This region of the protein contains an EMI domain. The EMI domain, first named after its presence in proteins of the Emilin family, is a small, cysteine-rich module of around 75 amino acids (Doliana et al. 2000). The EMI domain is found at the N-terminus of specific extracellular proteins ( $\beta$ igH3, Periostin, and Emilin's) that are capable of multimer formation. Although no direct interaction has been shown between Emilin family members and periostin, it is noted that Emilin1 and periostin co-localize within the developing heart, specifically in the forming valves and epicardium (Braghetta et al. 2002; Norris et al. 2004; Norris et al. 2008b). It has recently been demonstrated that periostin and $\beta$ igH3 heterodimerize via their EMI domains (Kim et al. 2009). This interaction was found to be essential for proper secretion of a periostin/ ßigH3 dimer. One further significance of the EMI domain is that this domain of Emilin1 inhibits TGF $\beta$ signaling by binding to the proform of TGF $\beta$ precursors, and prevents its maturation by furin convertases in the extracellular space. In addition to valve morphogenesis, the discovery of the EMI domain in periostin, with its function as a regulator of TGF $\beta$ processing and activation points to its potential importance in other adult disease processes, e.g. atherosclerosis, inflammation, tissue repair and fibrosis.

\section{Regulation of periostin expression}

Due to its clear importance in valve development and cardiac remodeling, factors regulating periostin expression are currently under investigation. To date, $\operatorname{TGF} \beta \mathrm{s} 1,2$, and 3, BMPs 2 and 4, VEGF, CCN2, Vitamin-K, valsartan (an angiotensin II antagonist), and interleukins 3, 4, 6 and 13 can all regulate periostin expression in a cell-specific context (Asano et al. 2005; Banerjee et al. 2009; Blanchard et al. 2008; Coutu et al. 2008; Iekushi et al. 2007; Inai et al. 2008; Norris et al. 2009; Shao and Guo 2004; Takayama et al. 2006). As pertains to cardiac development, the TGF $\beta$ s and BMPs appear to be the main mediators of periostin stimulation. In cushion mesenchyme, MEKK3 (mitogenactivated protein/ERK kinase kinase-3) was shown to stimulate TGF $\beta 2$ expression, which, in turn, activates periostin expression and promotes EMT (Stevens et al. 2008). Additionally, it was found that TGF $\beta 3$ stimulation of cushion mesenchymal cell explants in hanging drop cultures resulted in an increase in periostin and collagen expression, coincident with alterations in viscoelastic properties (Norris et al. 2009). These findings suggest that TGF $\beta$ stimulation of periostin expression results in the deposition of matrix, which correlates with stages of valve differentiation and maturation. It is not known whether expression of periostin in cushion mesenchyme occurs through the canonical Smad2/3 pathway or via the ERK/ MAP kinase pathway, although both pathways are likely avenues for its regulation. BMP-2 has also been shown to regulate periostin expression in cushion mesenchyme (Inai et al. 2008). Through BMP-2 activation of the ALK6 receptor (a type I BMP receptor), Smad1/5/8 activation occurs and the transcription factor Twist-1 is induced. Twist 1 is then capable of directly binding bind to, and positively regulating the periostin promoter (Connerney et al. 2006; Oshima et al. 2002; Vincentz et al. 2008). This, in turn, stimulates cushion mesenchyme migration. These responses can be abrogated by using a BMP-specific inhibitor (noggin), or a dominant negative ALK6 virus.

Although the promoter of periostin has been sequenced, and a number of conserved stretches identified, the only transcription factors that have been identified to date in regulating periostin expression in the heart are Twist1, SRF (a negative regulator of periostin), and YY1 (Ying Yang-1) 
(Lindsley et al. 2007; Niu et al. 2008; Oshima et al. 2002). As YY1 is reported to be a ubiquitously expressed transcription factor, it was striking that the periostin promoter segment harboring the YY1 binding element in transgenic mice only expressed the LacZ reporter gene in a subset of cardiac cells. The reason for this is not known, but probably involves a DNA-independent cardiac-specific co- activator with which YY1 can cooperate. It is clear that further studies are needed to identify specific promoter and enhancer sequences capable of driving periostin expression during development and disease. A schematic representation of the current understanding of periostin's effect on the molecular regulation and differentiation of mesenchymal cells (valve progenitor cells) is depicted in Fig. 2.

\section{Fibroblast Progenitor Cell}

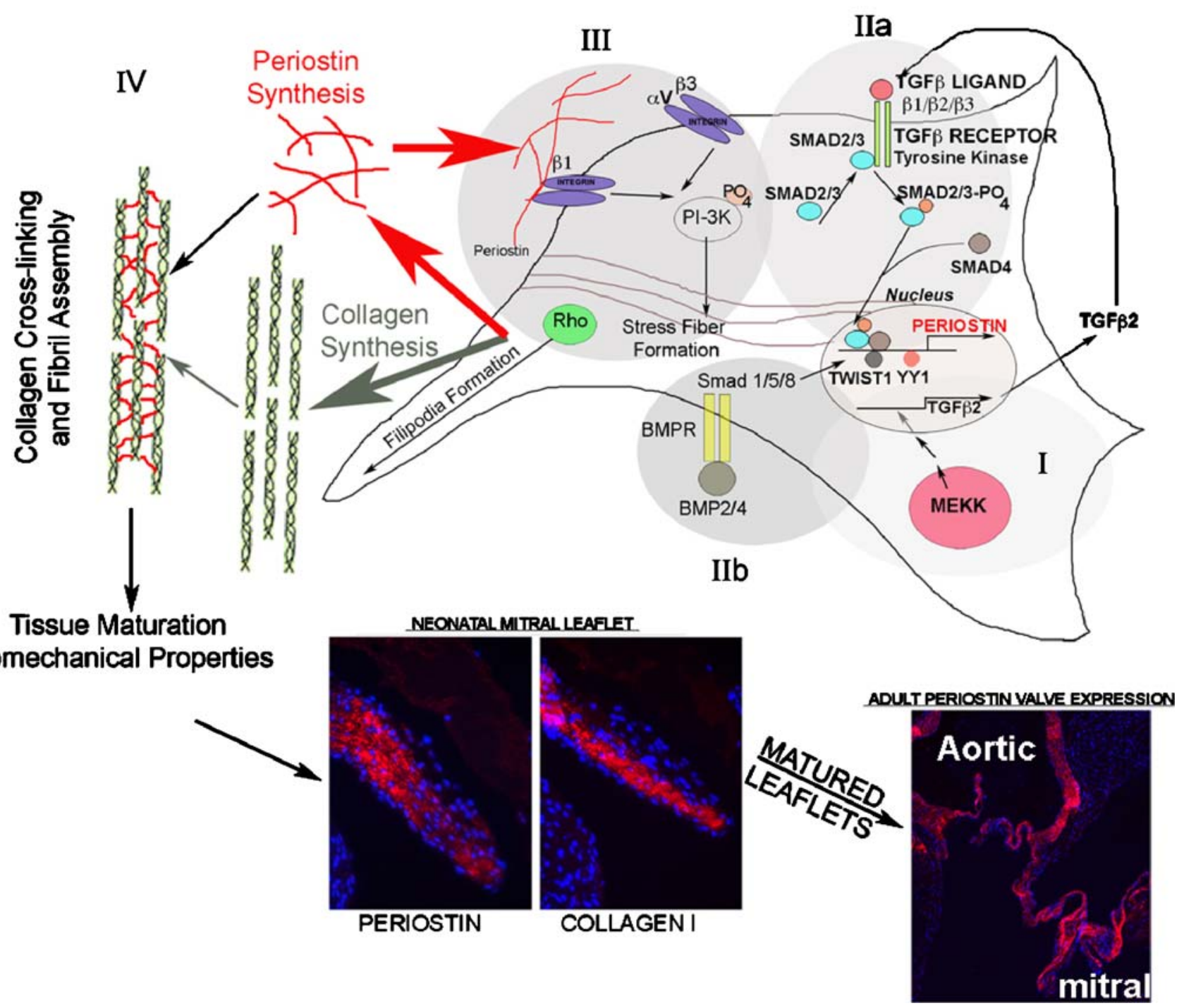

Fig. 2 Periostin molecular regulatory networks in fibroblast progenitor cells. MEKK stimulates TGF $\beta 2$ production (I) which is secreted and stimulates its canonical receptor (IIa) This stimulates downstream Smad phosphorylation and activation, which targets these proteins to the nucleus where they cooperate with cell-specific transcription factors to regulate the periostin promoter. It is not known whether these phospho-Smad proteins cooperate with Twist1, YY1, or SRF (known transcriptional regulators of periostin expression) to promote or repress periostin transcription. BMP $2 / 4$ (IIb) are known to act through the Smad 1/5/8 pathway to activate Twist1 and stimulate periostin expression. Periostin is secreted, after which it can interact with specific cell-surface receptors (III). In doing so, they stimulate intracellular signal cascades which involve, among other, PI3-Kinase and Rho kinase. This stimulates filipodia and actin reorganization (stress fiber formation) to mediate migration, adhesion, and fibroblast differentiation. Secreted periostin additionally regulates collagen fibrillogenesis via a promotion of collagen cross-linking (IV). Through these combined matricellular functions (receptor-mediated cell signaling and matrix interactions), periostin regulates the differentiation, maturation, and biomechanical properties of connective tissues, including skin, tendon, and heart valves 


\section{Clinical correlates}

Developmental defects in the ECM can have major implications that over time greatly affect valve function. Thus, even small changes in the composition (and alignment) of the valvular ECM can affect valve differentiation and ultimately compromise valve integrity, resulting in valvular and cardiovascular diseases. This is evident in Marfan Syndrome (Fibrillin-1 mutations), EDS (COL5A1, COL5A2, and COL1A2 mutations with involvement of tenascin-X, and COL1A1), and X-linked non-syndromic mitral valve prolapse (Filamin-A mutations). It is important to note that specific point mutations in these genes have been identified and are expressed throughout cardiac development. Indeed, we believe that there is not, nor should there be, a defined line separating development (including embryonic, fetal, neonatal) and adulthood. Adulthood is clearly a result of developmental processes acting in concert over time to form mature structures. Thus, adulthood, in its very essence, is a continuum of developmental processes. Of potential clinical relevance to periostin biology, EDS type II syndrome has been associated with an unbalanced $(6 \mathrm{q} ; 13 \mathrm{q})$ translocation which includes the locus for periostin at 13q13.3 (Scarbrough et al. 1984). In addition, patients with Rieger syndrome type II (who have assorted cardiovascular malformations, such as: aortic valvular stenosis, inter-atrial defects, congenital tricuspid valve anomaly, bicuspid aortic valve, etc.) have been assigned to chromosomal break points near the periostin locus (Mammi et al. 1998; Phillips et al. 1996; Stathacopoulos et al. 1987). To date, no mutations in the periostin gene have been identified as causal to a cardiac valvular disease. However, based on the tight connection between periostin and collagen, it would not be surprising to see periostin play a significant contributing role in congenital and/or acquired mitral and aortic valve disease.

\section{Summary}

Bornstein and colleagues have proposed that secreted extracellular matrix proteins that function more in regulation of cell-matrix interactions than as structural proteins constitute a functionally-related family of proteins called matricellular proteins (Bornstein 2000). Unlike structural proteins such as collagen, laminins and elastin, matricellular proteins derive their complex functions from their ability to interact with multiple cell-surface receptors (especially integrins), cytokines, growth factors, proteases, and structural proteins. Examples of matricellular proteins include thrombospondins, tenascin-C, osteopontin, CCN1, SPARC, and periostin. The expression of this unique family of ECM proteins is most prominent during development and growth or in response to injury. Based on its known biological roles as described in this review, we propose the "Periostin Hypothesis" which defines this protein as a crucial profibrogenic, anti-myocardial matricellular protein. Implicit in this definition is periostin's ability to promote fibroblast differentiation while inhibiting myocardial growth. Through its roles in growth factor stimulation, matrix interactions, integrin-mediated signals, and biomechanical responsiveness, periostin is presented herein as a "Maturagen" or a factor necessary for proper fibrous tissue development and maturation during development, pathophysiology, and disease.

Acknowledgments We would like to thank the following funding agencies for their support: NIH-NHLBI: HL33756 (R.R.M), NIHNCRR: COBRE P20RR016434-07 (R.R.M.); National Science Foundation: FIBRE EF0526854 (R.R.M. and R.A.N.); Foundation Leducq: Mitral 07CVD04 (R.A.N and R.R.M); SC INBRE: 5MO1RR001070-28 (R.A.N); and American Heart Association: 0765280U (R.A.N.).

Open Access This article is distributed under the terms of the Creative Commons Attribution Noncommercial License which permits any noncommercial use, distribution, and reproduction in any medium, provided the original author(s) and source are credited.

\section{References}

Aeschlimann D, Kaupp O, Paulsson M (1995) Transglutaminasecatalyzed matrix cross-linking in differentiating cartilage: identification of osteonectin as a major glutaminyl substrate. J Cell Biol 129:881-892

Asano M, Kubota S, Nakanishi T, Nishida T, Yamaai T, Yosimichi G, Ohyama K, Sugimoto T, Murayama Y, Takigawa M (2005) Effect of connective tissue growth factor (CCN2/CTGF) on proliferation and differentiation of mouse periodontal ligamentderived cells. Cell Commun Signal 3:11

Ausoni S, Sartore S (2009) From fish to amphibians to mammals: in search of novel strategies to optimize cardiac regeneration. J Cell Biol 184:357-364

Banerjee I, Yekkala K, Borg TK, Baudino TA (2006) Dynamic interactions between myocytes, fibroblasts, and extracellular matrix. Ann N Y Acad Sci 1080:76-84

Banerjee I, Fuseler JW, Price RL, Borg TK, Baudino TA (2007) Determination of cell type and number during cardiac development in the neonatal and adult rat and mouse. Am J Physiol Heart Circ Physiol. 293:H1883-1891

Banerjee I, Fuseler JW, Intwala AR, Baudino TA (2009) IL-6 loss causes ventricular dysfunction, fibrosis, reduced capillary density, and dramatically alters the cell populations of the developing and adult heart. Am J Physiol Heart Circ Physiol 296:H16941704

Baril P, Gangeswaran R, Mahon PC, Caulee K, Kocher HM, Harada T, Zhu M, Kalthoff H, Crnogorac-Jurcevic T, Lemoine NR (2007) Periostin promotes invasiveness and resistance of pancreatic cancer cells to hypoxia-induced cell death: role of the beta4 integrin and the PI3k pathway. Oncogene 26:2082-2094

Becker AE, Anderson RH, Durrer D, Wellens HJ (1978) The anatomical substrates of wolff-parkinson-white syndrome. A clinicopathologic correlation in seven patients. Circulation 57:870-879 
Blanchard C, Mingler MK, McBride M, Putnam PE, Collins MH, Chang G, Stringer K, Abonia JP, Molkentin JD, Rothenberg ME (2008) Periostin facilitates eosinophil tissue infiltration in allergic lung and esophageal responses. Mucosal Immunol 1:289-296

Borg TK, Markwald R (2007) Periostin: more than just an adhesion molecule. Circ Res 101:230-231

Borg TK, Rubin K, Lundgren E, Borg K, Obrink B (1984) Recognition of extracellular matrix components by neonatal and adult cardiac myocytes. Dev Biol 104:86-96

Bornstein P (2000) Matricellular proteins: an overview. Matrix Biol 19:555-556

Bradshaw AD, Puolakkainen P, Dasgupta J, Davidson JM, Wight TN, Helene Sage E (2003) SPARC-null mice display abnormalities in the dermis characterized by decreased collagen fibril diameter and reduced tensile strength. J Invest Dermatol 120:949-955

Braghetta P, Ferrari A, de Gemmis P, Zanetti M, Volpin D, Bonaldo P, Bressan GM (2002) Expression of the EMILIN-1 gene during mouse development. Matrix Biol 21:603-609

Butcher JT, Norris RA, Hoffman S, Mjaatvedt CH, Markwald RR (2006) Periostin promotes atrioventricular mesenchyme matrix invasion and remodeling mediated by integrin signaling through Rho/PI 3-kinase. Dev Biol. 302:256-266

Camelliti P, Borg TK, Kohl P (2005) Structural and functional characterisation of cardiac fibroblasts. Cardiovasc Res 65:40-51

Canty EG, Kadler KE (2002) Collagen fibril biosynthesis in tendon: a review and recent insights. Comp Biochem Physiol A Mol Integr Physiol 133:979-985

Canty EG, Kadler KE (2005) Procollagen trafficking, processing and fibrillogenesis. J Cell Sci 118:1341-1353

Carver W, Nagpal ML, Nachtigal M, Borg TK, Terracio L (1991) Collagen expression in mechanically stimulated cardiac fibroblasts. Circ Res 69:116-122

Chen CC, Lau LF (2009) Functions and mechanisms of action of CCN matricellular proteins. Int J Biochem Cell Biol 41:771-783

Christiansen DL, Huang EK, Silver FH (2000) Assembly of type I collagen: fusion of fibril subunits and the influence of fibril diameter on mechanical properties. Matrix Biol 19:409-420

Connerney J, Andreeva V, Leshem Y, Muentener C, Mercado MA, Spicer DB (2006) Twistl dimer selection regulates cranial suture patterning and fusion. Dev Dyn 235:1345-1357

Coutu DL, Wu JH, Monette A, Rivard GE, Blostein MD, Galipeau J (2008) Periostin, a member of a novel family of vitamin Kdependent proteins, is expressed by mesenchymal stromal cells. J Biol Chem 283:17991-18001

de la Cruz MR (1998) Living Morphogenesis of the Heart. Birkhauser, Boston

Chuva de Sousa Lopes SM, Feijen A, Korving J, Korchynskyi O, Larsson J, Karlsson S, ten Dijke P, Lyons KM, Goldschmeding R, Doevendans P, Mummery CL (2004) Connective tissue growth factor expression and Smad signaling during mouse heart development and myocardial infarction. Dev Dyn 231: $542-550$

Doliana R, Bot S, Bonaldo P, Colombatti A (2000) EMI, a novel cysteine-rich domain of EMILINs and other extracellular proteins, interacts with the $\mathrm{gClq}$ domains and participates in multimerization. FEBS Lett 484:164-168

Ducy P, Zhang R, Geoffroy V, Ridall AL, Karsenty G (1997) Osf2/ Cbfa1: a transcriptional activator of osteoblast differentiation. Cell 89:747-754

Feng Y, Walsh CA (2004) The many faces of filamin: a versatile molecular scaffold for cell motility and signalling. Nat Cell Biol 6:1034-1038

Gillan L, Matei D, Fishman DA, Gerbin CS, Karlan BY, Chang DD (2002) Periostin secreted by epithelial ovarian carcinoma is a ligand for alpha(V)beta(3) and alpha(V)beta(5) integrins and promotes cell motility. Cancer Res 62:5358-5364
Guignard JP (1986) Hypertension in the neonate. Clin Exp Hypertens Part A Theory Pract 8:723-739

Haudek SB, Gupta D, Dewald O, Schwartz RJ, Wei L, Trial J, Entman ML (2009) Rho Kinase-1 Mediates Cardiac Fibrosis by Regulating Fibroblast Precursor Cell Differentiation. Cardiovasc Res. (In Press) doi:10.1093/cvr/cvp135

Horiuchi K, Amizuka N, Takeshita S, Takamatsu H, Katsuura M, Ozawa H, Toyama Y, Bonewald LF, Kudo A (1999) Identification and characterization of a novel protein, periostin, with restricted expression to periosteum and periodontal ligament and increased expression by transforming growth factor beta. J Bone Miner Res 14:1239-1249

Iekushi K, Taniyama Y, Azuma J, Katsuragi N, Dosaka N, Sanada F, Koibuchi N, Nagao K, Ogihara T, Morishita R (2007) Novel Mechanisms of Valsartan on the Treatment of Acute Myocardial Infarction Through Inhibition of the Antiadhesion Molecule Periostin. Hypertension. 49:1409-1414

Inai K, Norris RA, Hoffman S, Markwald RR, Sugi Y (2008) BMP-2 induces cell migration and periostin expression during atrioventricular valvulogenesis. Dev Biol 315:383-396

Jones JE, Jose PA (2004) Neonatal blood pressure regulation. Semin Perinatol 28:141-148

Kadler KE, Holmes DF, Trotter JA, Chapman JA (1996) Collagen fibril formation. Biochem J 316(Pt 1):1-11

Kent AL, Kecskes Z, Shadbolt B, Falk MC (2007a) Blood pressure in the first year of life in healthy infants born at term. Pediatr Nephrol 22:1743-1749

Kent AL, Kecskes Z, Shadbolt B, Falk MC (2007b) Normative blood pressure data in the early neonatal period. Pediatr Nephrol 22:1335-1341

Kern CB, Hoffman S, Moreno R, Damon BJ, Norris RA, Krug EL, Markwald RR, Mjaatvedt CH (2005) Immunolocalization of chick periostin protein in the developing heart. Anat Rec A Discov Mol Cell Evol Biol 284:415-423

Kii I, Amizuka N, Minqi L, Kitajima S, Saga Y, Kudo A (2006) Periostin is an extracellular matrix protein required for eruption of incisors in mice. Biochem Biophys Res Commun 342:766-772

Kim H, Sengupta A, Glogauer M, McCulloch CA (2008) Filamin A regulates cell spreading and survival via betal integrins. Exp Cell Res 314:834-846

Kim BY, Olzmann JA, Choi SI, Ahn SY, Kim TI, Cho HS, Suh H, Kim EK (2009) Corneal dystrophy-associated H124H mutation disrupts TGFBIinteraction with periostin and causes mislocalization to the lysosome. J Biol Chem. (In Press) doi/10.1074/jbc.M109.013607.

Kolditz DP, Wijffels MC, Blom NA, van der Laarse A, Markwald RR, Schalij MJ, Gittenberger-de Groot AC (2007) Persistence of functional atrioventricular accessory pathways in postseptated embryonic avian hearts: implications for morphogenesis and functional maturation of the cardiac conduction system. Circulation 115:17-26

Kruzynska-Frejtag A, Machnicki M, Rogers R, Markwald RR, Conway SJ (2001) Periostin (an osteoblast-specific factor) is expressed within the embryonic mouse heart during valve formation. Mech Dev 103:183-188

Kuhn B, Del Monte F, Hajjar RJ, Chang YS, Lebeche D, Arab S, Keating MT (2007) Periostin induces proliferation of differentiated cardiomyocytes and promotes cardiac repair. Nat Med 13:962-969

Lindsley A, Li W, Wang J, Maeda N, Rogers R, Conway SJ (2005) Comparison of the four mouse fasciclin-containing genes expression patterns during valvuloseptal morphogenesis. Gene Expr Patterns 5:593-600

Lindsley A, Snider P, Zhou H, Rogers R, Wang J, Olaopa M, Kruzynska-Frejtag A, Koushik SV, Lilly B, Burch JB, Firulli AB, Conway SJ (2007) Identification and characterization of a novel Schwann and outflow tract endocardial cushion lineage-restricted periostin enhancer. Dev Biol 307:340-355 
Litvin J, Selim AH, Montgomery MO, Lehmann K, Rico MC, Devlin H, Bednarik DP, Safadi FF (2004) Expression and function of periostin-isoforms in bone. J Cell Biochem 92:1044-1061

Mammi I, De Giorgio P, Clementi M, Tenconi R (1998) Cardiovascular anomaly in Rieger syndrome: heterogeneity or contiguity? Acta Ophthalmol Scand 76:509-512

Mo FE, Lau LF (2006) The matricellular protein CCN1 is essential for cardiac development. Circ Res 99:961-969

Niu Z, Iyer D, Conway SJ, Martin JF, Ivey K, Srivastava D, Nordheim A, Schwartz RJ (2008) Serum response factor orchestrates nascent sarcomerogenesis and silences the biomineralization gene program in the heart. Proc Natl Acad Sci USA 105:17824-17829

Norris RA, Kern CB, Wessels A, Moralez EI, Markwald RR, Mjaatvedt CH (2004) Identification and detection of the periostin gene in cardiac development. Anat Rec A Discov Mol Cell Evol Biol 281:1227-1233

Norris RA, Kern CB, Wessels A, Wirrig EE, Markwald RR, Mjaatvedt $\mathrm{CH}$ (2005) Detection of betaig-H3, a TGFbeta induced gene, during cardiac development and its complementary pattern with periostin. Anat Embryol (Berl) 210:13-23

Norris RA, Damon B, Mironov V, Kasyanov V, Ramamurthi A, Moreno-Rodriguez R, Trusk T, Potts JD, Goodwin RL, Davis J, Hoffman S, Wen X, Sugi Y, Kern CB, Mjaatvedt CH, Turner DK, Oka T, Conway SJ, Molkentin JD, Forgacs G, Markwald RR (2007) Periostin regulates collagen fibrillogenesis and the biomechanical properties of connective tissues. J Cell Biochem 101:695-711

Norris RA, Borg TK, Banerjee I, Baudino TA, Butcher JT, Markwald RR (2008a) Neonatal and adult cardiovascular pathophysiological remodeling and repair: developmental role of periostin. Ann N Y Acad Sci 1123:30-40

Norris RA, Moreno-Rodriguez RA, Sugi Y, Hoffman S, Amos J, Hart MM, Potts JD, Goodwin RL, Markwald RR (2008b) Periostin regulates atrioventricular valve maturation. Developmental Biology 316:200-213

Norris RA, Potts JD, Yost MJ, Junor L, Brooks T, Tan H, Hoffman S, Hart MM, Kern MJ, Damon B, Markwald RR, Goodwin RL (2009) Periostin promotes a fibroblastic lineage pathway in atrioventricular valve progenitor cells. Dev Dyn 238:1052-1063

Ohta Y, Hartwig JH, Stossel TP (2006) FilGAP, a Rho- and ROCKregulated GAP for Rac binds filamin $A$ to control actin remodelling. Nat Cell Biol 8:803-814

Oka T, Xu J, Kaiser RA, Melendez J, Hambleton M, Sargent MA, Lorts A, Brunskill EW, Dorn GW 2nd, Conway SJ, Aronow BJ, Robbins J, Molkentin JD (2007) Genetic manipulation of periostin expression reveals a role in cardiac hypertrophy and ventricular remodeling.[see comment]. Circulation Research 101:313-321

Oshima A, Tanabe H, Yan T, Lowe GN, Glackin CA, Kudo A (2002) A novel mechanism for the regulation of osteoblast differentiation: transcription of periostin, a member of the fasciclin I family, is regulated by the bHLH transcription factor, twist. J Cell Biochem 86:792-804

Phillips JC, del Bono EA, Haines JL, Pralea AM, Cohen JS, Greff LJ, Wiggs JL (1996) A second locus for Rieger syndrome maps to chromosome 13q14. Am J Hum Genet 59:613-619

Politz O, Gratchev A, McCourt PA, Schledzewski K, Guillot P, Johansson S, Svineng G, Franke P, Kannicht C, Kzhyshkowska J, Longati P, Velten FW, Goerdt S (2002) Stabilin-1 and -2 constitute a novel family of fasciclin-like hyaluronan receptor homologues. Biochem J 362:155-164

Rios H, Koushik SV, Wang H, Wang J, Zhou HM, Lindsley A, Rogers R, Chen Z, Maeda M, Kruzynska-Frejtag A, Feng JQ, Conway
SJ (2005) periostin null mice exhibit dwarfism, incisor enamel defects, and an early-onset periodontal disease-like phenotype. Mol Cell Biol 25:11131-11144

Ruan K, Bao S, Ouyang G (2009) The multifaceted role of periostin in tumorigenesis. Cell Mol Life Sci. (In Press) doi: 10.1007/s00018009-0013-7.

Scarbrough PR, Daw J, Carroll AJ, Finley SC (1984) An unbalanced $(6 \mathrm{q} ; 13 \mathrm{q})$ translocation in a male with clinical features of EhlersDanlos type II syndrome. J Med Genet 21:226-228

Shao R, Guo X (2004) Human microvascular endothelial cells immortalized with human telomerase catalytic protein: a model for the study of in vitro angiogenesis. Biochem Biophys Res Commun 321:788-794

Shimazaki M, Nakamura K, Kii I, Kashima T, Amizuka N, Li M, Saito M, Fukuda K, Nishiyama T, Kitajima S, Saga Y, Fukayama M, Sata M, Kudo A (2008) Periostin is essential for cardiac healing after acute myocardial infarction. J Exp Med 205:295-303

Skonier J, Neubauer M, Madisen L, Bennett K, Plowman GD, Purchio AF (1992) cDNA cloning and sequence analysis of beta ig-h3, a novel gene induced in a human adenocarcinoma cell line after treatment with transforming growth factor-beta. DNA Cell Biol 11:511-522

Snider P, Hinton RB, Moreno-Rodriguez RA, Wang J, Rogers R, Lindsley A, Li F, Ingram DA, Menick D, Field L, Firulli AB, Molkentin JD, Markwald R, Conway SJ (2008) Periostin is required for maturation and extracellular matrix stabilization of noncardiomyocyte lineages of the heart. Circ Res 102:752-760

Stathacopoulos RA, Bateman JB, Sparkes RS, Hepler RS (1987) The Rieger syndrome and a chromosome 13 deletion. J Pediatr Ophthalmol Strabismus 24:198-203

Stevens MV, Broka DM, Parker P, Rogowitz E, Vaillancourt RR, Camenisch TD (2008) MEKK3 initiates transforming growth factor beta2-dependent epithelial-to-mesenchymal transition during endocardial cushion morphogenesis. Circ Res 103:1430-1440

Sugiura T, Takamatsu H, Kudo A, Amann E (1995) Expression and characterization of murine osteoblast-specific factor 2 (OSF-2) in a baculovirus expression system. Protein Expr Purif 6:305-311

Surveyor GA, Brigstock DR (1999) Immunohistochemical localization of connective tissue growth factor (CTGF) in the mouse embryo between days 7.5 and 14.5 of gestation. Growth Factors $17: 115-124$

Takayama G, Arima K, Kanaji T, Toda S, Tanaka H, Shoji S, McKenzie AN, Nagai H, Hotokebuchi T, Izuhara K (2006) Periostin: a novel component of subepithelial fibrosis of bronchial asthma downstream of IL-4 and IL-13 signals. J Allergy Clin Immunol 118:98-104

Takeshita S, Kikuno R, Tezuka K, Amann E (1993) Osteoblastspecific factor 2: cloning of a putative bone adhesion protein with homology with the insect protein fasciclin I. Biochem J 294(Pt 1):271-278

Terracio L, Tingstrom A, Peters WH 3 rd, Borg TK (1990) A potential role for mechanical stimulation in cardiac development. Ann N Y Acad Sci 588:48-60

Ueda K, Ohta Y, Hosoya H (2003) The carboxy-terminal pleckstrin homology domain of ROCK interacts with filamin-A. Biochem Biophys Res Commun 301:886-890

Vincentz JW, Barnes RM, Rodgers R, Firulli BA, Conway SJ, Firulli AB (2008) An absence of Twistl results in aberrant cardiac neural crest morphogenesis. Developmental Biology 320:131-139

Visconti RP, Markwald RR (2006) Recruitment of new cells into the postnatal heart: potential modification of phenotype by periostin. Ann N Y Acad Sci 1080:19-33

Zhou X, Boren J, Akyurek LM (2007) Filamins in cardiovascular development. Trends Cardiovasc Med 17:222-229 